Voix et Images

voixetimages

\title{
Littérature et recherche universitaire : la Question des revues
}

\section{Bernard Andrès}

Volume 12, numéro 2 (35), hiver 1987

Jacques Brault

URI : https://id.erudit.org/iderudit/200632ar

DOI : https://doi.org/10.7202/200632ar

Aller au sommaire du numéro

\section{Éditeur(s)}

Université du Québec à Montréal

\section{ISSN}

0318-9201 (imprimé)

1705-933X (numérique)

Découvrir la revue

\section{Citer cet article}

Andrès, B. (1987). Littérature et recherche universitaire : la Question des revues. Voix et Images, 12(2), 266-266. https://doi.org/10.7202/200632ar d'utilisation que vous pouvez consulter en ligne.

https://apropos.erudit.org/fr/usagers/politique-dutilisation/ 


\section{Littérature et recherche universitaire: la Question des revues}

Je ne reviendrai pas en détail sur. le programme de notre colloque de mars 1986 (reproduit dans le numéro 32 de Voix et images). L'objet de cette rencontre était de faire le point sur le type de questionnement que les revues universitaires font subir à la littérature et sur la façon dont elles ont évolué. depuis vingt ans, dans la mouvance théorique internationale.

Les textes suivants tentent de dégager à partir d'une analyse de chaque revue les grands courants qui ont marqué les études littéraires au Québec depuis une vingtaine d'années (pour remonter peu ou prou à la fondation de nos périodiques): histoire littéraire, édition critique, structuralisme, structuralisme génétique, sociologie littéraire, socio et psycho-critique, sémiotique, etc. Par-delà les effets de mode, quels rapports entretient la recherche québécoise avec les traditions européennes et américaines? Peut-on parler aujourd'hui de la constitution d'un corpus québécois (corpu's de textes littéraires, mais aussi de textes critiques de référence)? Ce qui court entre les lignes, c'est aussi le problème de la viabilité de nos revues placées de gré ou de force en situation de concurrence (l'intervention de Louise Milot aborde de front ce sujet). Quelle place et quel champ d'action Québec comme Ottawa entendent-il laisser à la recherche universitaire en études littéraires? Autant de questions que nous (nous) posons en interpellant non seulement les chercheur(e)s. mais aussi les principaux organismes subventionneurs impliqués dans la survie de nos revues.

Ả Voix et images, Ẽtudes françaises et Études littéraires, s’étaient jointes dans les débats Présence francophone, la Revue d'histoire littéraire du Québec et du Canada-français, ainsi que diverses revues et magazines littéraires québécois. Malheureusement, des restrictions d'ordre budgétaire nous empêchent de reproduire l'ensemble des interventions (consignées sur bande magnétique); ainsi que les allocutions d'ouverture et de clôture de Madame la Doyenne Monique Lefèbvre-Pinard et de Monsieur Claude Corbo, alors Vice-recteur à l'enseignement et à la recherche '. Que toutes, tous les participant(e)s soient ici remercié(e)s pour la dynamique instaurée dans les débats. Souhaitons qu'un prochain colloque ouvert à l'ensemble de la communauté littéraire et universitaire, aboutisse à une publication plus complète.

Bernard Andrès

1. Nous remercions le Décanat des études avancées et de la recherche de l'UQAM, qui a rendu possible cette manifestation, tout en contribuant aux frais de la présente publication des actes. 